\title{
Crystal structure and phase transition in noelbensonite: a multi- methodological study
}

\author{
G. Cametti $^{1}$ - T. Armbruster ${ }^{1} \cdot$ J. Hermann ${ }^{1} \cdot$ S. Churakov ${ }^{1,2}$
}

Received: 1 December 2016 / Accepted: 26 January 2017 / Published online: 3 March 2017

(C) Springer-Verlag Berlin Heidelberg 2017

\begin{abstract}
The crystal structure and the phase transition of noelbensonite $\left(\left(\mathrm{Ba}_{0.72} \mathrm{Sr}_{0.31} \mathrm{Ca}_{0.01}\right)_{\Sigma 1.05}\left(\mathrm{Mn}_{1.82} \mathrm{Al}_{0.16}\right)_{\Sigma 1.98}\right.$ $\left.\left[\mathrm{Si}_{2} \mathrm{O}_{7}\right](\mathrm{OH})_{2} \cdot \mathrm{H}_{2} \mathrm{O}\right)$ were investigated by in situ singlecrystal X-ray diffraction, $a b$ initio simulations, and infrared spectroscopy. In contrast to previous assumptions, single-crystal X-ray diffraction data and molecular dynamic simulations at room temperature (RT) displayed the acentric space group $P 2_{1} c n, a=6.31303(2), b=9.0977(3)$, $c=13.5820(4) \AA, \quad V=779.73(4) \AA^{3}$. This corresponds to the low-temperature $\left(-118^{\circ} \mathrm{C}\right)$ structure of lawsonite $\left(\mathrm{CaAl}_{2}\left[\mathrm{Si}_{2} \mathrm{O}_{7}\right](\mathrm{OH})_{2} \cdot \mathrm{H}_{2} \mathrm{O}\right)$ and to the phase of hennomartinite $\left(\mathrm{SrMn}^{+3}{ }_{2}\left[\mathrm{Si}_{2} \mathrm{O}_{7}\right](\mathrm{OH})_{2} \cdot \mathrm{H}_{2} \mathrm{O}\right)$ below $95^{\circ} \mathrm{C}$. At $225^{\circ} \mathrm{C}$, the structure changed to space group $\mathrm{Cmcm}$, which corresponds to that of hennomartinite at $>245^{\circ} \mathrm{C}$ and of lawsonite above $0^{\circ} \mathrm{C}$. In this structure the oxygen site of the $\mathrm{H}_{2} \mathrm{O}$ molecule showed positional disorder. Molecular dynamic simulations indicated that the splitting of this site reflects the disordered arrangement of the hydroxyl groups and the $\mathrm{H}_{2} \mathrm{O}$ molecule in the high-temperature modification. Infrared spectra collected at RT showed similarities with those of lawsonite. The bands at 3566 and $3517 \mathrm{~cm}^{-1}$ and the two broader bands between 3300 and $2930 \mathrm{~cm}^{-1}$ agree with the stretching frequencies of the hydrogen bond system as calculated from X-ray diffraction data and
\end{abstract}

Electronic supplementary material The online version of this article (doi:10.1007/s00269-017-0876-3) contains supplementary material, which is available to authorized users.

G. Cametti

georgia.cametti@krist.unibe.ch

1 Institute of Geological Sciences, University of Bern, Baltzerstr. 1-3, 3012 Bern, Switzerland

2 Laboratory for Waste Management, Paul Scherrer Institute, Villingen, Switzerland theoretical computations. Normal mode analysis of molecular dynamic trajectories allowed to identify the origin of vibration bands and polarization dependence of the IR spectra.

Keywords Noelbensonite $\cdot$ X-ray diffraction $\cdot$ Phase transition $\cdot$ Lawsonite group

\section{Introduction}

Noelbensonite $\mathrm{BaMn}^{+3}{ }_{2}\left[\mathrm{Si}_{2} \mathrm{O}_{7}\right](\mathrm{OH})_{2} \cdot \mathrm{H}_{2} \mathrm{O}$ is a member of the lawsonite group and the barium analogue of hennomartinite $\mathrm{SrMn}_{2}^{+3}{ }_{2}\left[\mathrm{Si}_{2} \mathrm{O}_{7}\right](\mathrm{OH})_{2} \cdot \mathrm{H}_{2} \mathrm{O}$. This mineral was firstly described by Kawachi et al. (1996). X-ray powder diffraction suggested for the room temperature structure the space group Cmcm (Kawachi et al. 1996).

Similar to hennomartinite, the structure consists of $\mathrm{MnO}_{6}$ octahedra, which form edge-sharing chains parallel to $a$, interconnected by $\mathrm{Si}_{2} \mathrm{O}_{7}$ groups. The interstices are mainly occupied by $\mathrm{H}_{2} \mathrm{O}$ and $\mathrm{Ba}$. The chemical composition of noelbensonite (Lucchetti et al. 1988; Kawachi et al. 1996) exhibits substitution of Ba by variable amount of $\mathrm{Ca}$ and Sr. Moreover, electron microprobe (EMP) analyses of a sample from the Woods mine (New South Wales, Australia) showed unusual high $\mathrm{Ca}$ content suggesting a hypothetical $\mathrm{Ca}$ end-member of a noelbensonite solid-solution series (Coombs et al. 2004). The structures of lawsonite and hennomartinite are characterized by reversible temperaturedependent phase transitions originating from the change of the hydrogen bond-system. This induces the symmetry evolution $P 2_{1} \mathrm{cn} \rightarrow \mathrm{Pmcn} \rightarrow \mathrm{Cmcm}$. Corresponding structural transformations were detected in lawsonite at -118 and $0{ }^{\circ} \mathrm{C}$ whereas in hennomartinite they are shifted toward higher temperatures, at 95 and $150^{\circ} \mathrm{C}$, respectively 


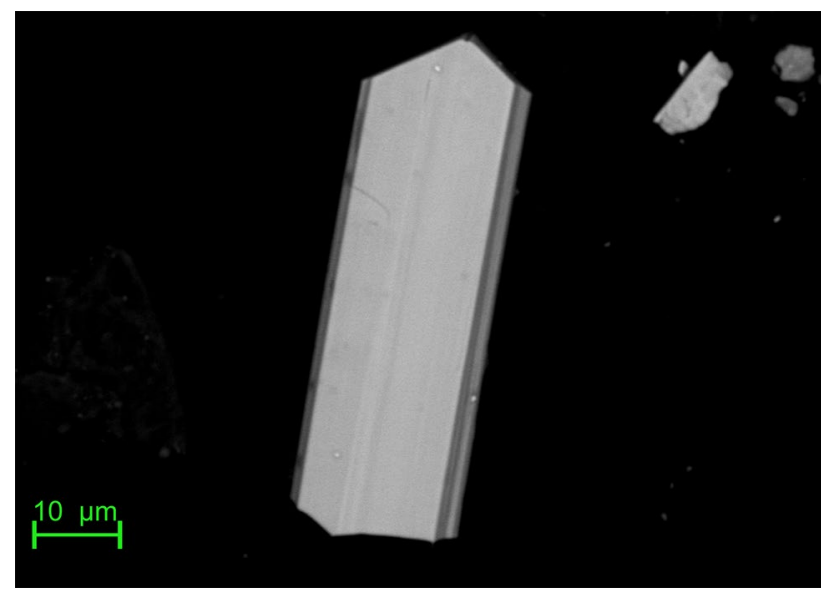

Fig. 1 SEM picture of a single crystal of noelbensonite represented by a platy needle elongated parallel to $a$-axis

Table 1 Results of semi-quantitative analyses of noelbensonite and lawsonite as obtained from SEM-EDX. The chemical composition of lawsonite by Baur (1978) is reported for comparison

\begin{tabular}{llll}
\hline & $\begin{array}{l}\text { Lawsonite (Baur } \\
1978)\end{array}$ & Lawsonite & Noelbensonite \\
\hline $\mathrm{wt} \%$ & & & \\
$\mathrm{Mn}_{2} \mathrm{O}_{3}$ & & & $35(1)$ \\
$\mathrm{Al}_{2} \mathrm{O}_{3}$ & 31.09 & $32(1)$ & $1.8(6)$ \\
$\mathrm{SiO}_{2}$ & 37.75 & $37(1)$ & $27.7(8)$ \\
$\mathrm{CaO}$ & 17.18 & $19(2)$ & $0.12(20)$ \\
$\mathrm{Fe}_{2} \mathrm{O}_{3}$ & 0.90 & $1.6(8)$ & \\
$\mathrm{SrO}$ & & & $7.4(7)$ \\
$\mathrm{BaO}$ & & & $25(1)$ \\
$\mathrm{H}_{2} \mathrm{O}^{\mathrm{a}}$ & 11.5 & 11.5 & 7.5 \\
$\mathrm{a} . \mathrm{p.f.u}$ & & & \\
$\mathrm{Mn}$ & & & $1.82(7)$ \\
$\mathrm{Al}$ & 1.95 & $2.03(5)$ & $0.16(5)$ \\
$\mathrm{Si}$ & 2.01 & $1.99(6)$ & $2.00(4)$ \\
$\mathrm{Ca}$ & 0.98 & $1.09(13)$ & $0.009(18)$ \\
$\mathrm{Fe}$ & 0.04 & $0.06(3)$ & \\
$\mathrm{Sr}$ & & & $0.31(3)$ \\
$\mathrm{Ba}$ & & & $0.72(4)$ \\
$\mathrm{OH}$ & 2 & 2 & 2 \\
$\mathrm{H}_{2} \mathrm{O}$ & 1 & 1 & 1 \\
\hline
\end{tabular}

${ }^{\mathrm{a}} \mathrm{H}_{2} \mathrm{O}$ and $\mathrm{OH}$ content according to stoichiometry

(Libowitzky and Armbruster 1995, 1996). In addition, more recent studies (Salje et al. 2011, 2012) focused on ferroelectric hysteresis measurements of a natural sample of lawsonite; their results indicated a slightly lower temperature $\left(-148^{\circ} \mathrm{C}\right)$ for the $P 2_{1} c n \rightarrow P m c n$ phase transition.

The aim of this study is to investigate the crystal structure of noelbensonite under ambient conditions and to determine whether the mineral undergoes similar phase transitions at high temperatures as revealed for the other lawsonite-group members (Libowitzky and Armbruster 1995, 1996). Our goal is to compare these new results with those obtained for hennomartinite and lawsonite in order to understand the influence of the chemical composition on the structural behavior. Experimental data obtained from in situ single-crystal X-ray diffraction coupled with infrared spectroscopy and theoretical calculations from molecular dynamic simulations are presented.

\section{Experimental section}

\section{Chemical analysis}

The sample of noelbensonite used in the present study originates from M. Cerchiara, Faggiona, La Spezia (Italy). At this locality, the mineral occurs in manganiferous mineralizations in metacherts of Jurassic ophiolitic sequences (Lucchetti et al. 1988). The chemical composition was measured by SEM-EDX using a ZEISS EVO50 instrument with an EDAX TEAM system. An investigation by electron microprobe (EMP) was not possible due to the sample morphology that resulted in very thin and platy crystals with an average size of ca. $0.01 \times 0.02 \times 0.08 \mathrm{~mm}$ (Fig. 1). Operating conditions were: $20 \mathrm{kV}$ accelerating voltage, $10 \mathrm{~mm}$ working distance, $0^{\circ}$ tilt angle. Chemical data were collected at 21 analytical points on five different crystals. The final crystal chemical formula was calculated by normalizing the chemical composition with an assumed water content of 8\% (Lucchetti et al. 1988; Kawachi et al. 1996) on the basis of 16 positive charges.

To evaluate the quality of SEM-EDX data, additional chemical analyses were performed on a sample of lawsonite with a known chemical composition (Baur 1978). The lawsonite is from Cazadero, Sonora County, California and was analyzed under the same analytical conditions as reported for noelbensonite. The chemical composition of lawsonite (Table 1) agrees with corresponding EMP reference data (Baur 1978), therefore our SEM analyses are considered reliable.

\section{Infrared spectroscopy}

Infrared spectra were recorded at room temperature on a Bruker Hyperion 3000 IR microscope with a liquid nitrogen-cooled MCT detector coupled to a Tensor II spectrometer. The crystal investigated was the same as that used for $\mathrm{X}$-ray data collection and was kept in its original mount on a glass fiber. The sample was placed in a Perspex chamber that was continuously flushed with dry air. The aperture was set to a square with $50 \mu \mathrm{m}$ side length. Measurements consisted of 128 scans with a spectral resolution of $4 \mathrm{~cm}^{-1}$. 
Polarized spectra were collected with a gold wire grid on $\mathrm{ZnSe}$ polarizer. The spectra were corrected for small variations in atmospheric $\mathrm{CO}_{2}$ and $\mathrm{H}_{2} \mathrm{O}$ using the Bruker OPUS software and baseline correction was done using the concave rubberband algorithm with 64 baseline points and three iterations.

\section{Ab initio simulations}

Refinement of structural positions of hydrogen atoms was performed with electronic structure calculations based on spin-polarized density functional theory (DFT) using the Gaussian and Plane Waves method (GPW) as implemented in the CP2K simulation package (VandeVondele et al. 2005). The electron exchange and correlations were described by Perdew-Burke-Ernzerhof (PBE) functional (Perdew et al. 1996, 1997). The Kohn-Sham orbitals were expanded using a linear combination of atomcentered Gaussian-type orbital functions. In this study a "short range" double- $\xi$ valence polarized basis set for each atomic kind was used (VandeVondele and Hutter 2007). This basis set was developed for simulations of condensed matter systems and was proven to provide accurate structural and thermochemical results. Core electrons were described by dual space norm-conserving pseudopotentials (Hartwigsen et al. 1998). The electron charge density was expanded using an auxiliary basis set of plane waves up to a 600 Ry cutoff. Dispersion correction, which is essential for DFT simulations of hydrogen bond systems, was taken into account using the DFT + D3 method (Grimme 2007). To improve the description of partially occupied $3 \mathrm{~d}$ states in $\mathrm{Mn}$ atoms, the DFT + U correction schema was applied. The effective Hubbard parameter was set to $2 \mathrm{eV}$, in agreement with previous calculations of Mn-bearing systems (Cockayne et al. 2013). Several geometry optimization attempts were performed starting from different positions of hydrogen atoms as suggested by the analysis of the differential electron density in X-ray refinements. The optimized configurations were used again in the structure refinements in an iterative way to obtain the lowest energy configuration which produces the best R-factor in refinement. For each force evaluation step, the energy was converged to within a value of $7 \times 10^{-10} \mathrm{au} / \mathrm{atom}$. The simulations were performed in a $2 \times 1 \times 1$ supercell with the composition $8 \times\left[\mathrm{BaMn}_{2} \mathrm{Si}_{2} \mathrm{O}_{7}(\mathrm{OH})_{2} \cdot \mathrm{H}_{2} \mathrm{O}\right]$ using a single $\mathrm{k}$-point in the origin of the Brillouin zone ( $\Gamma$-point sampling). The electronic structure was solved for antiferromagnetic arrangement and the spin of $\mathrm{Mn}$ atoms aligned parallel to [001].

Born-Oppenheimer molecular dynamics (MD) simulations were performed in the NVT (constant number of atoms, volume, and temperature) ensemble applying a canonical velocity scaling thermostat with 0.5 fs integration time per step. The IR spectra and vibrational density of state (VDOS) were obtained as Fourier transform of total (electronic and ionic) dipole and velocity autocorrelation functions, respectively (Churakov and Wunder 2004). The time evolution of the electronic dipole moment was derived from the localized Wannier orbitals (Resta 1994). The trajectory analyses were performed using the TRAVIS postprocessing tool (Brehm and Kirchner 2011).

\section{Single-crystal X-ray diffraction}

A crystal with dimensions of approximately $0.01 \times 0.03 \times 0.08 \mathrm{~mm}$ was glued on the tip of a glass fiber and mounted on a goniometer head. X-ray diffraction data were collected on a Bruker APEXII diffractometer with MoK $\alpha$ radiation $(\lambda=0.71073 \AA$ ), using a CCD area detector. The phase transitions were monitored in situ by means of a self-constructed temperature-controlled hot-nitrogen blower $(1.4 \mathrm{~L} / \mathrm{min})$.

Diffraction data were measured at RT, 100, 150, 200, 275 , and $325^{\circ} \mathrm{C}$. After this first heating excursion the crystal was cooled down and a new dataset was measured at room temperature. A second temperature-dependent data collection was performed on the same crystal at 250, 225, $200,150,100^{\circ} \mathrm{C}$, and RT. In this second experiment, the sample was kept at $250^{\circ} \mathrm{C}$ for ca. $10 \mathrm{~h}$ (data collection time) and then stepwise cooled down to RT. Finally, additional data were collected at 275 and $325^{\circ} \mathrm{C}$. The data were integrated and an empirical absorption correction was applied using the Apex 2v. 2011.4-1 software package. Structures were solved using SHELXTL 2008 (Sheldrick 2008).

In contrast to previous assumptions (Kawachi et al. 1996), diffraction data of noelbensonite at RT displayed the non-centrosymmetric space group $P 2_{1} c n$. This space group was suggested by the occurrence of several $C$-centering forbidden reflections ( $h k l$, with $h+k=2 n+1$ ), which persisted up to $200^{\circ} \mathrm{C}$. Structural data obtained from 225 to $325^{\circ} \mathrm{C}$ were solved in the space group $\mathrm{Cmcm}$.

Structural refinements were carried out by SHELXL 2013 (Sheldrick 2015), using neutral atomic scattering factors. Starting values of atomic coordinates and labels of the heteropolyhedral framework atoms were those reported in Libowitzky and Armbruster (1996) for the hennomartinite structure.

In the low-temperature modification with space group $P 2_{1} c n$, the crystal exhibited inversion twinning with refined twin components $0.83(2) / 0.17(2)$. The refined twin fraction of noelbensonite measured at RT after the first heating excursion (up to $325^{\circ} \mathrm{C}$ ) corresponded to $0.65(2) / 0.35(2)$. The occurrence of a small percentage of $\mathrm{Ca}$ and the amount of $\mathrm{Sr}$ was taken into account by refining the Ba site as partially occupied by Sr. According to the determined chemical composition we refined 
the octahedral sites with scattering factors of $\mathrm{Mn}$ and $\mathrm{Al}$. Hydrogen positions were extracted from difference Fourier maps. Restraints on bond distances $\mathrm{H}-\mathrm{O}=0.97(2)$ $\AA$ were applied and the $\mathrm{H}$ positions were refined with fixed isotropic displacement parameters $\left(U=0.05 \AA^{2}\right)$. Additional restraints on $\mathrm{H} \cdots \mathrm{O}$ distances $\mathrm{Hw} \cdots \mathrm{O} 23$ $[d=2.16(5) \AA), \mathrm{H} 41 \cdots \mathrm{Ow}(d=2.10(5) \AA]$ were used in $P 2{ }_{1} c n$ structure refinements, according to geometry optimization. From 225 to $325^{\circ} \mathrm{C}$, oxygen at the $\mathrm{Ow}$ site was refined at a split position $x=0.04$, with Ow-Ow separated by $0.52(3) \AA$.

Data collection and refinement parameters of the noelbensonite structure at room temperature and $275^{\circ} \mathrm{C}$ are reported in Table 2. Bond-valence calculations were performed using the parameters by Brese and O'Keeffe (1991) and Ferraris and Ivaldi (1988).

\section{Results}

The chemical formula of noelbensonite as computed from EDX-SEM chemical analyses was $\left(\mathrm{Ba}_{0.72} \mathrm{Sr}_{0.31} \mathrm{Ca}_{0.01}\right)_{\Sigma 1.05}\left(\mathrm{Mn}_{1.82} \mathrm{Al}_{0.16}\right)_{\Sigma 1.98}\left[\mathrm{Si}_{2} \mathrm{O}_{7}\right](\mathrm{OH})_{2}$ $\cdot \mathrm{H}_{2} \mathrm{O}$ (Table 1).

Atomic parameters of the noelbensonite structures at $\mathrm{RT}$ and $275^{\circ} \mathrm{C}$ as obtained from X-ray diffraction data are reported in Tables 3 and 4, respectively. Table 5 compares the hydrogen bond systems of the $P 2_{1} \mathrm{cn}$ and $\mathrm{Cmcm}$ structures determined by $\mathrm{X}$-ray diffraction with those estimated by MD simulations. A comparison of the stretching frequencies of the hydrogen bonds as obtained by IR spectroscopy with those calculated from X-ray and MD simulated $\mathrm{H}-\mathrm{O}$ and $\mathrm{O}-\mathrm{O}$ distances is reported in Table 6.

Table S1 in the supplementary materials reports the bond distances and angles of the structures refined at
Table 2 Crystal data and refinement parameters for noelbensonite at room temperature (RT) and $275^{\circ} \mathrm{C}$ (relative humidity $=0$ )

\begin{tabular}{|c|c|c|}
\hline Crystal data & Noelbensonite RT & Noelbensonite $275^{\circ} \mathrm{C}$ \\
\hline$a$ axis $(\AA)$ & $6.3103(2)$ & $6.3136(8)$ \\
\hline$b$ axis $(\AA)$ & $9.0977(3)$ & $9.1410(13)$ \\
\hline$c$ axis $(\AA)$ & $13.5820(4)$ & $13.619(2)$ \\
\hline Cell volume $\left(\AA^{3}\right)$ & $779.73(4)$ & $785.97(19)$ \\
\hline$Z$ & 4 & 4 \\
\hline Space Group & $P 2_{1} c n$ & $\mathrm{Cmcm}$ \\
\hline Refined chemical formula & $\begin{array}{l}\left(\mathrm{Ba}_{0.75} \mathrm{Sr}_{0.24}\right)_{\Sigma 0.99}\left(\mathrm{Mn}_{1.89} \mathrm{Al}_{0.11}\right) \\
{ }_{\Sigma 2}\left[\mathrm{Si}_{2} \mathrm{O}_{7}\right](\mathrm{OH})_{2} \cdot \mathrm{H}_{2} \mathrm{O}\end{array}$ & $\begin{array}{l}\left(\mathrm{Ba}_{0.74} \mathrm{Sr}_{0.25}\right)_{\Sigma 0.99}\left(\mathrm{Mn}_{1.87}\right. \\
\left.\mathrm{Al}_{0.13}\right)_{\Sigma 2}\left[\mathrm{Si}_{2} \mathrm{O}_{7}\right](\mathrm{OH})_{2} \\
\cdot \mathrm{H}_{2} \mathrm{O}\end{array}$ \\
\hline \multicolumn{3}{|l|}{ Intensity measurement } \\
\hline Diffractometer & APEX II SMART & \\
\hline $\mathrm{X}$-ray radiation & $\operatorname{Mo} K \alpha \lambda=0.71073 \AA$ & \\
\hline X-ray power & $50 \mathrm{kV}, 30 \mathrm{~mA}$ & \\
\hline Monochromator & Graphite & \\
\hline Temperature $\left({ }^{\circ} \mathrm{C}\right)$ & 25 & 275 \\
\hline Time per frame & 60 & 60 \\
\hline Max. $2 \theta$ & $66.28^{\circ}$ & $68.57^{\circ}$ \\
\hline Index ranges & $\begin{array}{l}-9<h<8 \\
-12<k<13 \\
-15<l<20\end{array}$ & $\begin{array}{l}-9<h<9 \\
-12<k<14 \\
-21<l<15\end{array}$ \\
\hline No. of measured reflections & 9506 & 4739 \\
\hline No. of unique reflections & 2761 & 901 \\
\hline No. of observed reflections $I>2 \sigma(I)$ & 1483 & 731 \\
\hline \multicolumn{3}{|l|}{ Structure refinement } \\
\hline No. of parameters used in the refinement & $151+8$ restraints & $54+2$ restraints \\
\hline$R$ (int) & 0.0416 & 0.0392 \\
\hline$R(\sigma)$ & 0.0519 & 0.0356 \\
\hline GooF & 0.945 & 1.090 \\
\hline$R 1, \mathrm{I}>2 \sigma(I)$ & 0.0278 & 0.0304 \\
\hline$R 1$, all data & 0.0710 & 0.0440 \\
\hline w $R 2\left(\right.$ on $\left.F^{2}\right)$ & 0.0584 & 0.0572 \\
\hline$\Delta \rho_{\min }\left(-\mathrm{e} \AA^{-3}\right)$ close to & $-1.00 \mathrm{Sr}$ & $-1.46 \mathrm{Sr}$ \\
\hline$\Delta \rho_{\max }\left(\mathrm{e} \AA^{-3}\right)$ close to & $0.96 \mathrm{Sr}$ & $0.89 \mathrm{Sr}$ \\
\hline
\end{tabular}


Table 3 Atomic coordinates, displacement parameters, and occupancies of noelbensonite $P 2{ }_{1}$ cn structure at room temperature

\begin{tabular}{lcccll}
\hline Site & $x$ & $y$ & $z$ & $U^{e q}$ & Occ. \\
\hline $\mathrm{Ba}$ & $0.01756(2)$ & $0.31449(4)$ & $0.25109(6)$ & $0.00971(10)$ & $0.754(10)$ \\
$\mathrm{Sr}$ & $0.01756(2)$ & $0.31449(4)$ & $0.25109(6)$ & $0.00971(10)$ & $0.246(10)$ \\
$\mathrm{Mn}$ & $0.23737(19)$ & $0.25688(17)$ & $-0.00588(16)$ & $0.0075(5)$ & $0.946(8)$ \\
$\mathrm{Al}$ & $0.23737(19)$ & $0.25688(17)$ & $-0.00588(16)$ & $0.0075(5)$ & $0.054(8)$ \\
$\mathrm{Mn} 1$ & $0.2440(2)$ & $0.25165(17)$ & $0.50446(17)$ & $0.0070(5)$ & $0.946(8)$ \\
$\mathrm{A} 11$ & $0.2440(2)$ & $0.25165(17)$ & $0.50446(17)$ & $0.0070(5)$ & $0.054(8)$ \\
$\mathrm{Si}$ & $-0.0076(6)$ & $0.9726(3)$ & $0.1299(2)$ & $0.0077(7)$ & 1 \\
$\mathrm{Si} 1$ & $-0.0099(6)$ & $0.9688(3)$ & $0.3673(2)$ & $0.0077(8)$ & 1 \\
O1 & $-0.0333(7)$ & $0.0054(5)$ & $0.2484(7)$ & $0.0134(10)$ & 1 \\
O2 & $0.2773(13)$ & $0.3793(8)$ & $0.1044(5)$ & $0.0097(16)$ & 1 \\
O21 & $0.2800(14)$ & $0.3826(8)$ & $0.3984(5)$ & $0.0110(17)$ & 1 \\
O22 & $-0.2941(13)$ & $-0.3751(8)$ & $-0.1151(6)$ & $0.0118(18)$ & 1 \\
O23 & $-0.3035(13)$ & $-0.3624(8)$ & $-0.3791(6)$ & $0.0128(17)$ & 1 \\
O3 & $0.0019(12)$ & $0.1336(7)$ & $0.0801(5)$ & $0.0115(17)$ & 1 \\
O31 & $0.0042(12)$ & $0.1269(7)$ & $0.4183(5)$ & $0.0121(17)$ & 1 \\
O4 & $-0.0112(9)$ & $0.6397(7)$ & $0.0457(5)$ & $0.0125(19)$ & 1 \\
O41 & $-0.0215(10)$ & $0.6311(7)$ & $0.4637(5)$ & $0.0099(17)$ & 1 \\
Ow & $-0.0446(9)$ & $0.6257(6)$ & $0.2448(7)$ & $0.0264(14)$ & 1 \\
Hw & $0.064(12)$ & $0.681(9)$ & $0.281(6)$ & $0.05^{\mathrm{a}}$ & 1 \\
Hw1 & $-0.037(16)$ & $0.659(11)$ & $0.178(3)$ & $0.05^{\mathrm{a}}$ & 1 \\
H4 & $0.055(18)$ & $0.552(8)$ & $0.022(7)$ & $0.05^{\mathrm{a}}$ & 1 \\
H41 & $-0.073(15)$ & $0.589(10)$ & $0.404(3)$ & $0.05^{\mathrm{a}}$ & 1 \\
\hline
\end{tabular}

${ }^{\mathrm{a}}$ Fixed
Table 4 Atomic coordinates, displacement parameters, and occupancies of noelbensonite $\mathrm{Cmcm}$ structure at $275^{\circ} \mathrm{C}$

\begin{tabular}{llllll}
\hline Site & $x$ & $y$ & $z$ & $U^{e q}$ & Occ. \\
\hline $\mathrm{Ba}$ & 0 & $0.31610(4)$ & $1 / 4$ & $0.01902(12)$ & $0.747(10)$ \\
$\mathrm{Sr}$ & 0 & $0.31610(4)$ & $1 / 4$ & $0.01902(12)$ & $0.253(10)$ \\
$\mathrm{Mn}$ & $1 / 4$ & $1 / 4$ & 0 & $0.01245(17)$ & $0.935(8)$ \\
$\mathrm{Al}$ & $1 / 4$ & $1 / 4$ & 0 & $0.01245(17)$ & $0.065(8)$ \\
$\mathrm{Si}$ & 0 & $0.97207(11)$ & $0.13110(7)$ & $0.0117(3)$ & 1 \\
$\mathrm{O} 1$ & 0 & $0.0033(5)$ & $1 / 4$ & $0.0266(10)$ & 1 \\
$\mathrm{O} 2$ & $0.2877(3)$ & $0.3771(2)$ & $0.10895(14)$ & $0.0205(5)$ & 1 \\
$\mathrm{O} 3$ & 0 & $0.1322(3)$ & $0.0821(2)$ & $0.0179(6)$ & 1 \\
$\mathrm{O} 4$ & 0 & $0.6382(3)$ & $0.0434(2)$ & $0.0215(6)$ & 1 \\
$\mathrm{Ow}$ & $0.040(2)$ & $0.6234(8)$ & $1 / 4$ & $0.042(4)$ & 0.5 \\
$\mathrm{Hw}$ & 0 & $0.669(6)$ & $0.190(2)$ & $0.05^{\mathrm{a}}$ & 1 \\
$\mathrm{Hh}$ & 0 & $0.536(2)$ & $0.054(4)$ & $0.05^{\mathrm{a}}$ & 1 \\
\hline
\end{tabular}

${ }^{\mathrm{a}}$ Fixed

25 and $275^{\circ} \mathrm{C}$. Bond valence analyses of the $P 2{ }_{1} c n$ and $\mathrm{Cmcm}$ phases of noelbensonite are shown in Tables S2a and S2b. Cif files of the structures were submitted as supplementary material.

\section{X-ray diffraction}

Figure 2 shows the trend of the unit-cell volume as a function of temperature corresponding to the first heating cycle, the cooling cycle, and the second heating excursion. From RT to $200^{\circ} \mathrm{C}$, no appreciable differences between the unit-cell dimensions obtained during the two temperaturedependent datasets were seen. The volume difference, evaluated in multiple measurements, at 275 and $325^{\circ} \mathrm{C}$, was less than $3 \sigma$ and was considered insignificant. Moreover, structural refinements performed on datasets collected during different heating/cooling cycles did not show appreciable differences at corresponding temperatures. The refined occupancy (ca. 0.06) of Al at the octahedral sites is in good agreement with that obtained by SEM-EDX chemical data. $\mathrm{Sr}$ substitutes to $25 \%$ at the Ba site (occupancy refinement), which agrees within $2 \sigma$ with the compositional data (Table 1). In our experiments, the phase transition from space group $P 2_{1} \mathrm{cn}$ to $\mathrm{Cmcm}$ occurred at $225^{\circ} \mathrm{C}$.

\section{$P 2_{1} c n$ structure}

The structure of noelbensonite under ambient conditions was solved and successfully refined in the space group 
Table 5 Hydrogen bond system of noelbensonite at room temperature and at $275^{\circ} \mathrm{C}$ according to singlecrystal (SC) X-ray data and molecular dynamic simulations. Bond distances $(\AA), \mathrm{D}-\mathrm{H} \cdots \mathrm{A}$, $\mathrm{D}-\mathrm{H}-\mathrm{A}$, and $\mathrm{H}-\mathrm{O}-\mathrm{H}$ angles $\left(^{\circ}\right)$ are reported

\begin{tabular}{|c|c|c|c|c|c|}
\hline Hydrogen bond & D-H & $\mathrm{H} \cdots \mathrm{A}$ & $\mathrm{D} \cdots \mathrm{A}$ & $<(\mathrm{DHA})$ & $<(\mathrm{HOH})$ \\
\hline \multicolumn{6}{|l|}{ SC X-ray diffraction } \\
\hline \multicolumn{6}{|l|}{$P 2{ }_{1} c n 25^{\circ} \mathrm{C}$} \\
\hline $\mathrm{Ow}-\mathrm{Hw} \cdots \mathrm{O} 23$ & $0.98(3)$ & $2.29(4)$ & $3.207(11)$ & $157(8)$ & \multirow[t]{4}{*}{$106.1(14)$} \\
\hline $\mathrm{Ow}-\mathrm{Hw} 1 \cdots \mathrm{O} 4$ & $0.96(3)$ & $1.81(5)$ & $2.715(11)$ & $156(10)$ & \\
\hline $\mathrm{O} 4-\mathrm{H} 4 \cdots \mathrm{O} 41$ & $0.95(3)$ & $1.91(8)$ & $2.705(7)$ & $139(10)$ & \\
\hline $\mathrm{O} 41-\mathrm{H} 41 \cdots \mathrm{Ow}$ & $0.95(3)$ & $2.19(5)$ & $2.978(11)$ & $138(6)$ & \\
\hline \multicolumn{6}{|l|}{$\mathrm{Cmcm} 275^{\circ} \mathrm{C}$} \\
\hline $\mathrm{Ow}-\mathrm{Hw} \cdots \mathrm{O} 4^{\prime}$ & $0.942(19)$ & $2.02(4)$ & $2.829(3)$ & $142(4)$ & \multirow[t]{2}{*}{$108.8(11)$} \\
\hline $\mathrm{O} 4-\mathrm{Hh} \cdots \mathrm{O} 44^{\prime}$ & $0.935(20)$ & $2.08(4)$ & $2.788(6)$ & $131(4)$ & \\
\hline \multicolumn{6}{|l|}{ MD simulations } \\
\hline \multicolumn{6}{|l|}{$P 2_{1} c n 25^{\circ} \mathrm{C}$} \\
\hline $\mathrm{Ow}-\mathrm{Hw} \cdots \mathrm{O} 23$ & 0.982 & 2.176 & 3.264 & 155.3 & \\
\hline $\mathrm{Ow}-\mathrm{Hw} 1 \cdots \mathrm{O} 4$ & 1.025 & 1.624 & 2.633 & 168.8 & \\
\hline $\mathrm{O} 4-\mathrm{H} 4 \cdots \mathrm{O} 41$ & 1.015 & 1.685 & 2.683 & 168.3 & \\
\hline $\mathrm{O} 41-\mathrm{H} 41 \cdots \mathrm{Ow}$ & 0.982 & 2.075 & 2.964 & 149.8 & \\
\hline \multicolumn{6}{|l|}{$\mathrm{Cmcm} 275^{\circ} \mathrm{C}$} \\
\hline Ow-Hw...... $4^{\prime}$ & 1.001 & 1.819 & 2.762 & 147.7 & \\
\hline $\mathrm{O} 4-\mathrm{Hh} \cdots \mathrm{O} 4^{\prime}$ & 0.997 & 1.950 & 2.844 & 149.8 & \\
\hline
\end{tabular}

Symmetry codes: $\mathrm{O} 23=x+1 / 2,-y+1 / 2,-z, \mathrm{O} 41=x,-y+1, z-1 / 2, \mathrm{O} 4^{\prime}=-x, 1-y,-z$

Table 6 Assignment of experimental and calculated IR bands. Corresponding stretching frequencies $\left(\mathrm{cm}^{-1}\right)$ calculated according to $\mathrm{H}_{\cdots} \cdots \mathrm{O}$ distances as obtained by SC X-ray and MD results using correlation equations by Libowitzky (1999) are reported

\begin{tabular}{|c|c|c|c|c|c|c|c|}
\hline \multirow[t]{2}{*}{ IR experimental } & \multirow[b]{2}{*}{ Hydrogen bond } & \multicolumn{2}{|l|}{ SC X-ray } & \multicolumn{2}{|l|}{ MD } & \multicolumn{2}{|l|}{ IR calculated } \\
\hline & & $\mathrm{d}(\mathrm{H} \cdots \mathrm{O})^{\mathrm{a}}$ & $\mathrm{d}(\mathrm{O} \cdots \mathrm{O})^{\mathrm{b}}$ & $\mathrm{d}(\mathrm{H} \cdots \mathrm{O})^{\mathrm{a}}$ & $\mathrm{d}(\mathrm{O} \cdots \mathrm{O})^{\mathrm{b}}$ & & Hydrogen bond \\
\hline 3566 & $\mathrm{Ow}-\mathrm{Hw} \cdots \mathrm{O} 23$ & 3589 & 3583 & 3561 & 3586 & 3602 & $\mathrm{O} 41-\mathrm{H} 41 \cdots \mathrm{Ow}$ \\
\hline 3517 & $\mathrm{O} 41-\mathrm{H} 41 \cdots \mathrm{Ow}$ & 3567 & 3542 & 3518 & 3537 & $3570-3481$ doublet & $\begin{array}{c}\text { Ow-Hw‥O23; } \\
\text { Ow- } \\
\text { Hw‥O41 }\end{array}$ \\
\hline $3300-3000$ & $\mathrm{O} 4-\mathrm{H} 4 \cdots \mathrm{O} 41$ & 3387 & 3203 & 2935 & 3132 & $3200-2900$ & $\mathrm{O} 4-\mathrm{H} 4 \cdots \mathrm{O} 41$ \\
\hline 2930 & $\mathrm{Ow}-\mathrm{Hw} 1 \cdots \mathrm{O} 4$ & 3241 & 3231 & 2706 & 2921 & $2791-2566$ & 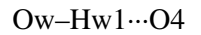 \\
\hline
\end{tabular}

${ }^{\mathrm{a}} v=3632-1.79 \times 10^{6} \exp (-d / 0.2146) ; d=\mathrm{H} \cdots \mathrm{O}$

${ }^{\mathrm{b}} v=3592-304 \times 10^{9} \exp (-d / 0.1321) ; d=\mathrm{O} \cdots \mathrm{O}$

$P 2{ }_{1}$ cn with final $R=2.78 \%$ (Tables 2,3 ). Similar to hennomartinite, it was found to be twinned by inversion with final refined twin contribution of $0.83(2) / 0.17(2)$.

The structure corresponds essentially to that of hennomartinite under ambient conditions (Libowitzky and Armbruster 1996) with the difference that $\mathrm{Sr}$ is mainly replaced by Ba (Fig. 3a). Both octahedra Mn and Mn1 display four short and two long $\mathrm{Mn}-\mathrm{O}$ distances (Table S1), indicating the Jahn-Teller distortion effect characteristic of $\mathrm{Mn}^{3+}$ in octahedral coordination.

The $\mathrm{Ba}$ site is eightfold coordinated by seven bonds to framework oxygen and one to the oxygen at the Ow site. The structural channels running along $a$ are slightly wider compared to those in hennomartinite, as a consequence of the larger $\mathrm{Ba}^{2+}$ cation. This also leads to stretching of the structure along $c$ with a corresponding $\mathrm{Si}-\mathrm{O} 1-\mathrm{Si} 1$ angle of $146.8(3)$ in hennomartinite to $155.5(4)^{\circ}$ in noelbensonite (Table S1).

The hydrogen bond-system determined by the experimental results indicated the occurrence of two strong and two weak hydrogen bonds (Table 5). The hydrogen atoms of the $\mathrm{H}_{2} \mathrm{O}$ molecule, at the $\mathrm{Hw}$ and $\mathrm{Hw} 1$ sites, form one weak Ow-Hw...O23 and one strong Ow-Hw1...O4 connection with H...A (A: acceptor) distances of 2.29(4) and 1.81(5) $\AA$, respectively. The hydrogen at $\mathrm{H} 41$, belonging to the hydroxyl group (O41) bonded to the $\mathrm{Mn}$ site, forms a rather weak bond to the oxygen of the $\mathrm{H}_{2} \mathrm{O}$ $(\mathrm{H} \cdots \mathrm{A}=2.19(5) \AA)$ whereas the one at $\mathrm{H} 4$ links to the oxygen $\mathrm{O} 41$ of the opposite $\mathrm{OH}$ group through a stronger interaction $(\mathrm{H} \cdots \mathrm{A}=1.91(8) \AA)$. 


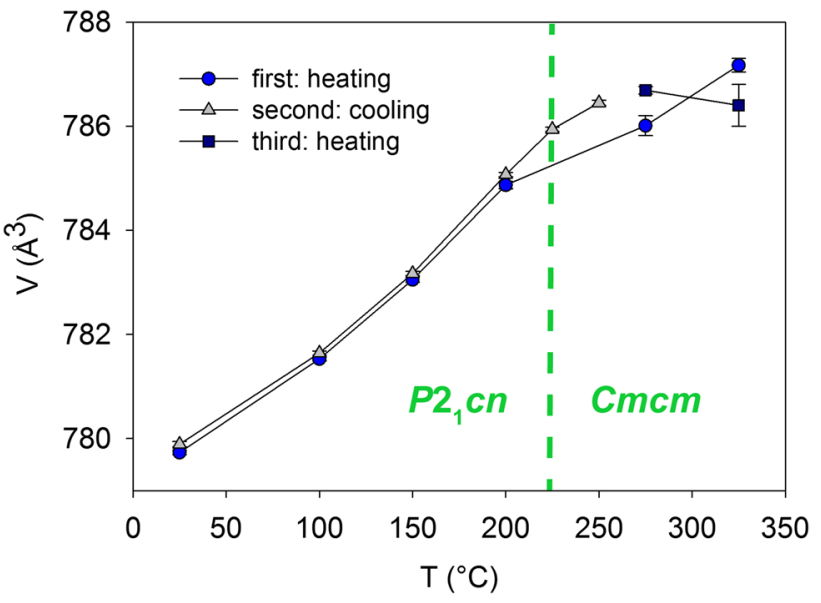

Fig. 2 Unit-cell volume of noelbensonite as a function of temperature. Different heating/cooling cycles are shown

\section{Cmcm structure}

The $\mathrm{Cmcm}$ structure of noelbensonite measured at $275^{\circ} \mathrm{C}$ is shown in Fig. 3b. Corresponding to hennomartinite, we refined the $\mathrm{H}_{2} \mathrm{O}$ molecule ( $\mathrm{Ow}$ site) at a split atom position with $x=0.04$ (Table 4), leading to the separation of Ow-Ow by 0.52 (3) $\AA$. This model was suggested by a high value of the atomic displacement parameter along the $a$ direction $\left(U^{11}=0.13 \AA^{2}\right.$ ), which characterized the Ow site if refined at a special position $(0, y, 1 / 4)$.
The hydrogen-bond net of noelbensonite at $275^{\circ} \mathrm{C}$ showed rather weak hydrogen bonds (Table 5) with donor (D) acceptor (A) distances $>2.70 \AA$ and DHA angles $<140^{\circ}$. The oxygen at Ow resides on the mirror plane perpendicular to [001] and it bonds to one Hw at $(x, y, z)$ and the corresponding symmetry equivalent site at $(x, y$, $-z+1 / 2)$. The hydrogen at $\mathrm{Hh}$ of the hydroxyl group $\mathrm{O} 4 \mathrm{Hh}$ is at 2.08(4) $\AA$ from the oxygen at the $\mathrm{O} 4$ site $(-x, 1-y$, $-z$ ) of the opposite octahedron, leading to a system of parallel hydrogen bonds (Fig. 3b). In addition, the oxygen at the $\mathrm{O} 4$ site acts as an acceptor for hydrogen $\mathrm{Hw}$ of the $\mathrm{H}_{2} \mathrm{O}$ molecule. Our findings show that the structure corresponds to those of hennomartinite at $245^{\circ} \mathrm{C}$ and of lawsonite above $0{ }^{\circ} \mathrm{C}$.

\section{Infrared}

Infrared spectra of noelbensonite collected at RT are reported in Fig. 4. For a better comparison with IR spectra of lawsonite and hennomartinite (Libowitzky and Rossman 1996), the spectra are divided into two wavelength ranges 4500-2500 and 1800-1400 $\mathrm{cm}^{-1}$. Two spectra are shown, the one polarized approximately parallel to $a$ and the unpolarized one. A polarized spectrum approximately perpendicular to the $a$ direction was also measured (fig. S1 in supplementary material), however, due to only approximate crystal orientation the spectral features represented mixed contributions of $b$ and $c$ components and it was not relevant for the interpretation of the results.
Fig. 3 Noelbensonite structure a at RT $\left(P 2{ }_{1} c n\right)$ and $\mathbf{b}$ at $275^{\circ} \mathrm{C}$ $(\mathrm{Cmcm})$, including site labels. Hydrogen bonds are represented by dotted lines whereas cylinders indicate $\mathrm{H}-\mathrm{O}$ and $\mathrm{Ba}-\mathrm{O}$ bonds
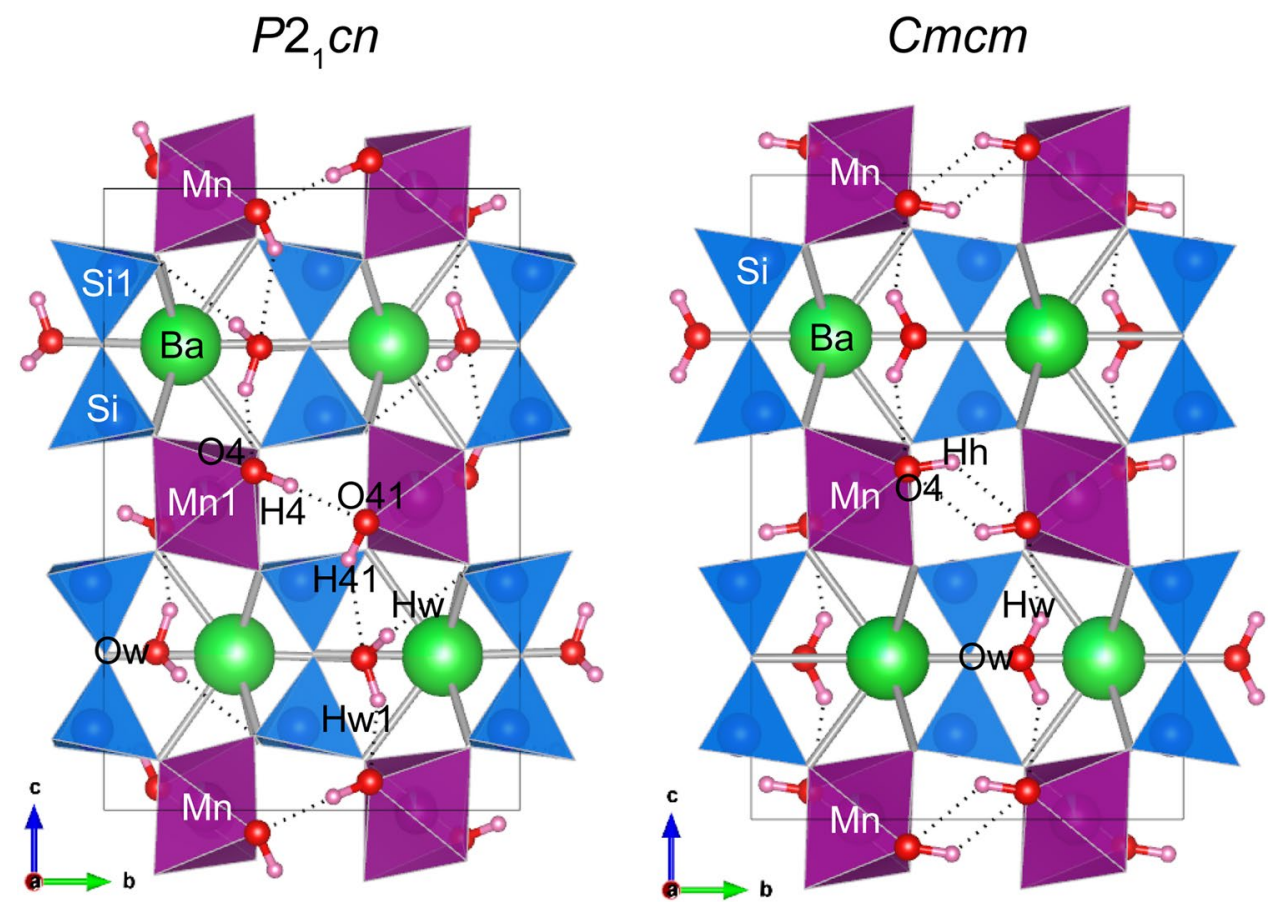

(a) (b) 


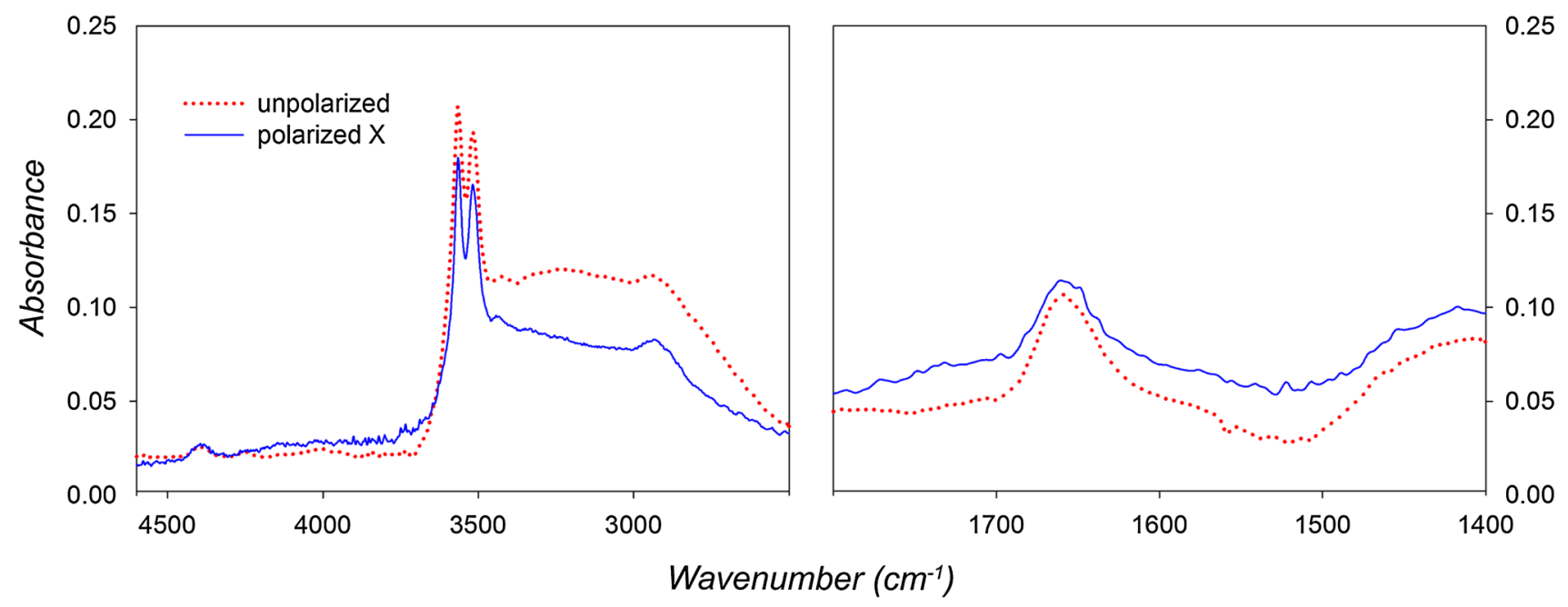

Fig. 4 Polarized (parallel to approximately $a$ ) and unpolarized infrared spectra of noelbensonite showing $\mathrm{H}_{2} \mathrm{O} / \mathrm{OH}$ specific absorptions

In general, the spectra in Fig. 4 show two strong bands at 3566 and $3517 \mathrm{~cm}^{-1}$ and a broad band between 2960 and $2940 \mathrm{~cm}^{-1}$. The band at $3566 \mathrm{~cm}^{-1}$ corresponds to $\mathrm{H}$... O distances between 2.0 and $2.2 \AA$ and to $\mathrm{O} \cdots \mathrm{O}$ distances between 3.0 and $3.2 \AA$ in agreement with experimental H... (2.287 $\AA$ ) and $\mathrm{O} \cdots \mathrm{O}(3.207 \AA)$ distances of the Ow-Hw...O23 interaction (Libowitzky 1999). Similarly, the stretching frequency at $3517 \mathrm{~cm}^{-1}$ is assigned to the $\mathrm{O} 41-\mathrm{H} 41 \cdots \mathrm{O}$ connection that shows shorter $\mathrm{H} \cdots \mathrm{O}$ (2.193 $\AA$ ) and O...O (2.978 $\AA$ ) distances. The broad peak at $2930 \mathrm{~cm}^{-1}$ corresponds to $\mathrm{H} \cdots \mathrm{O}$ distances between 1.7 and $1.9 \AA$ and to $\mathrm{O} \ldots \mathrm{O}$ distances between 2.6 and $2.7 \AA$. Thus, we assigned this band to the Ow-Hw1... 4 hydrogen bond.

A big hump occurs in the 3300 and $3000 \mathrm{~cm}^{-1}$ regions of the unpolarized spectrum but it is not as evident in the $a$-polarized one. This peak is assigned to the remaining $\mathrm{O} 4-\mathrm{H} 4 \cdots \mathrm{O} 41$ hydrogen bond, which is predominantly oriented along the $b$ axis and thus not evident in the $a$ direction. The band at $1660 \mathrm{~cm}^{-1}$ represents the bending mode of the $\mathrm{H}_{2} \mathrm{O}$ molecule, whereas the weak peak at $4393 \mathrm{~cm}^{-1}$, corresponds to the metal-OH motion (Libowitzky and Rossman 1996).

Our spectra have the same general features as those recorded on lawsonite (Libowitzky and Rossman 1996). In contrast, the unpolarized hennomartinite spectrum recorded at $\mathrm{RT}$ on a $\mathrm{KBr}$ pellet (Libowitzky and Rossman 1996) showed only one sharp stretching band at $3550 \mathrm{~cm}^{-1}$ and one intense broad band near 2800-2900 $\mathrm{cm}^{-1}$. Such features were interpreted as an exact overlap of the two high-energy bands and by very similar positions of the low-energy bands (Libowitzky and Rossman 1996).

\section{Molecular dynamic simulations}

$\mathrm{Ab}$ initio geometry optimization and molecular dynamic simulations confirmed the hydrogen positions determined by X-ray experiments. In general, the $\mathrm{H}$... O distances estimated by the experimental and theoretical approach were in good agreement (Table 5). The DHA angles of the $\mathrm{O} 4-\mathrm{H} 4 \cdots \mathrm{O} 41$ and $\mathrm{O} 41-\mathrm{H} 41 \cdots \mathrm{Ow}$ connections calculated at room temperature were $168.3^{\circ}$ and $149.8^{\circ}$, respectively. Corresponding values from $\mathrm{X}$-ray refinements are significantly smaller $\left(139.25^{\circ}\right.$ and $\left.138.49^{\circ}\right)$ as a consequence of the energetically optimized hydrogen positions in the simulations.

Molecular dynamic trajectories allowed further investigation of the splitting of the oxygen at the Ow site observed in the $\mathrm{Cmcm}$ structure. Figure 5 reports the running coordination number $\mathrm{RCN}(d)$ calculated for the $\mathrm{Hw}-\mathrm{Ow}$, $\mathrm{Hw} \cdots \mathrm{O} 4$, and $\mathrm{Hh} \cdots \mathrm{Ow}$ interactions in the $\mathrm{Cmcm}$ structure obtained at $327^{\circ} \mathrm{C}$. The graph is useful in understanding how many particles surround a determined atom at a given distance. As an example, the blue curve ( $\mathrm{Hw}-\mathrm{Ow}$ ) shows that each hydrogen at the Hw site is surrounded by one oxygen at Ow at ca. $1 \AA$. The green curve, corresponding to the $\mathrm{Hw} \cdots \mathrm{O} 4$ bond distance, indicates a coordination number between 0.6 and 0.7 (instead of ca. 1) at about 2.0 and $2.3 \AA$. This suggests that the oxygen at $\mathrm{O} 4$ does not always act as an acceptor for the hydrogen at $\mathrm{Hw}$, but these interactions are only present to ca. $65 \%$. In addition, $\mathrm{H} 4$ of the hydroxyl group is partially bonded $[\operatorname{RCN}(d)=0.1-0.2]$ within 2.1-2.3 $\AA$ to the oxygen of the $\mathrm{H}_{2} \mathrm{O}$ molecule (Ow). Such a connection, $\mathrm{Hh} \cdots \mathrm{Ow}$, corresponds to the $\mathrm{H} 41 \cdots \mathrm{Ow}$ bond found in the $P 2_{1} c n$ structure at lower temperature. Thus, the splitting of the Ow site reflects the disordered 


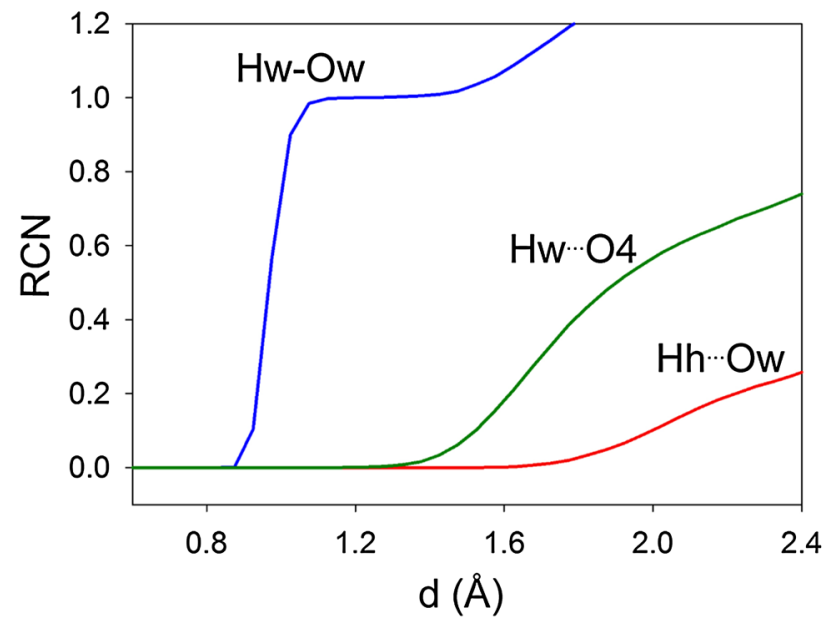

Fig. 5 Calculated running coordination number $\mathrm{RCN}(d)$ of the Hw-

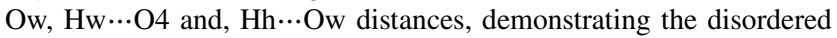
arrangement of the hydrogen bond-system in space group $\mathrm{Cmcm}$ arrangement of the hydroxyl groups and $\mathrm{H}_{2} \mathrm{O}$ molecules in the high-temperature modification.

The IR spectra and vibrational density of state (VDOS) obtained from MD simulations at RT are reported in Fig. 6a, b, respectively. The calculated polarized $(a, b, c)$ IR spectra (Fig. 6a) indicate that the bands between 3200 and $2600 \mathrm{~cm}^{-1}$ are mainly due to stretching of $\mathrm{OH}$ bonds oriented along the $b$ and $c$ axes. Analysis of VDOS, calculated individually for each $\mathrm{OH}$ site, allows detailed assignment of the vibration frequencies. In particular, the $\mathrm{O} 4-\mathrm{H} 4$ bond is the one which mainly contributes to the absorption band at $2988 \mathrm{~cm}^{-1}$, whereas the Ow-Hw1 is responsible for the absorption at $2785 \mathrm{~cm}^{-1}$ (Fig. 6b). This well agrees with the orientation of the $\mathrm{O} 4-\mathrm{H} 4$ and $\mathrm{Ow}-\mathrm{Hw} 1$ vectors, along $b$ and $c$, respectively, as estimated from X-ray diffraction data (Fig. 3a). According to table 3, the O4-H4 vector is also slightly tilted toward the $a$ axis (the difference between the $\mathrm{x}$ coordinates of $\mathrm{O} 4$ and $\mathrm{H} 4$ is ca. 0.06). Careful inspection of the calculated spectrum polarized along $a$ (Fig. 6a inlet) reveals a very weak and broadened component between 2750 and $3000 \mathrm{~cm}^{-1}$.

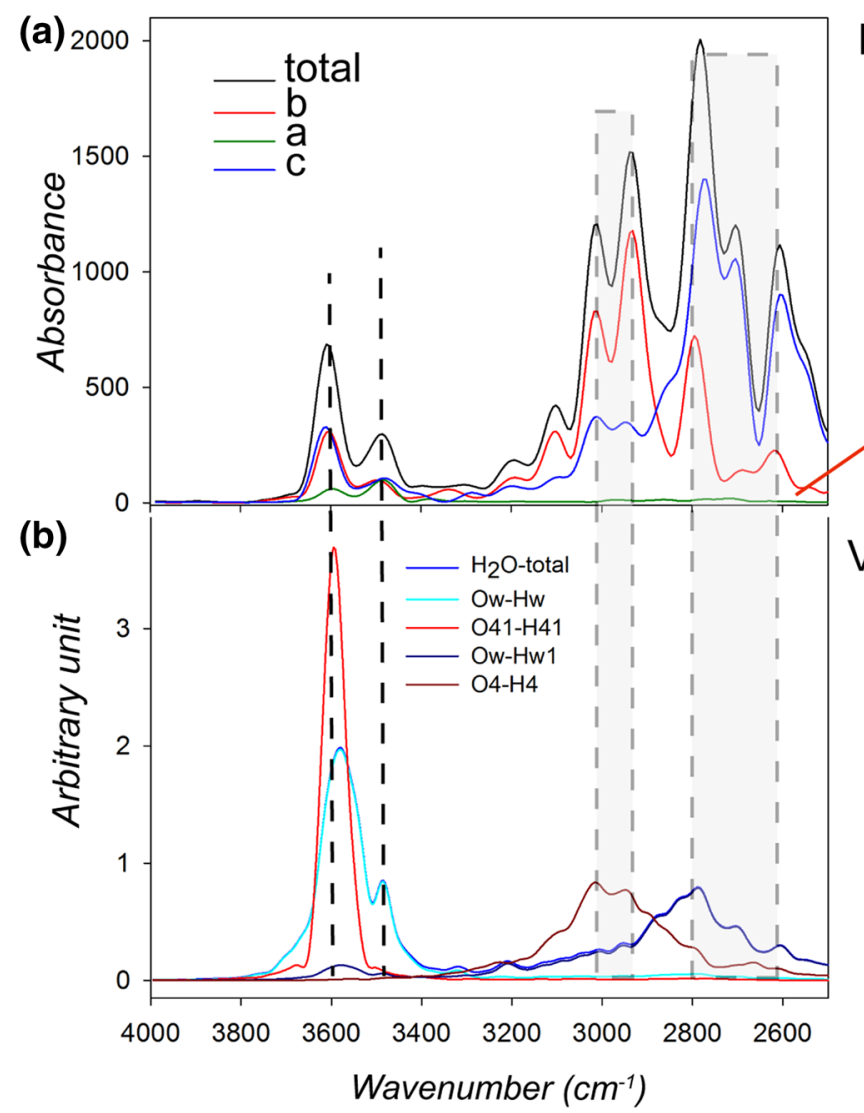

Fig. 6 a Calculated infrared spectra (absorbance on an arbitrary scale) and $\mathbf{b}$ VDOS curves of noelbensonite at RT. a The inlet shows a magnified view of the calculated IR spectrum polarized along $a$. b
IR

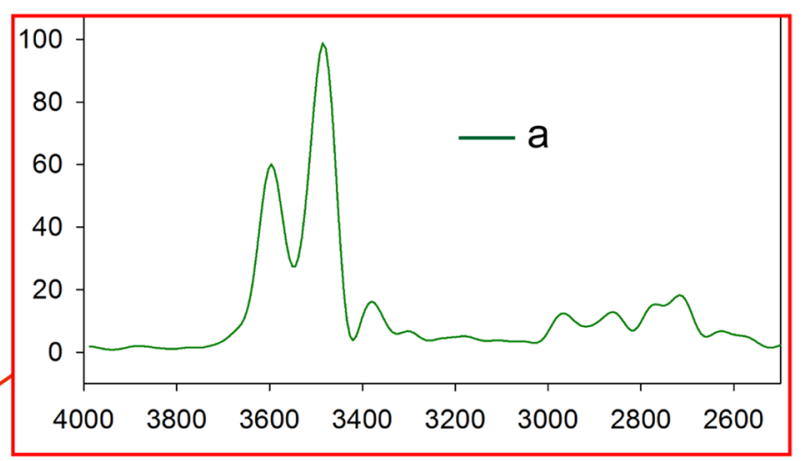

VDOS

The $\mathrm{H}_{2} \mathrm{O}$ total VDOS curve (light blue) overlaps with the $\mathrm{Ow}-\mathrm{Hw}$ contribution (cyan) at high frequency, and with the Ow-Hw1 (dark blue) at lower frequency 
The $\mathrm{O} 41-\mathrm{H} 41$ stretching results in the highest frequency band at $3591 \mathrm{~cm}^{-1}$ and the $\mathrm{Ow}-\mathrm{Hw}$ stretching in a double peak at 3570 and $3481 \mathrm{~cm}^{-1}$ (Fig. 6b). The O41-H41 bond is predominantly oriented along $b$ and $c$ (weak component along $a$ ) whereas the $\mathrm{Ow}-\mathrm{Hw}$ bond has an intermediate orientation between the three axes (Fig. 3a). Thus, molecular dynamics simulations suggest that the highest frequency band at $3602 \mathrm{~cm}^{-1}$ arises from the overlap of the hydroxyl group ( $b$ and $c$ components are almost the same and the $a$ one is weaker) and $\mathrm{H}_{2} \mathrm{O}$ stretching vibrations. The one at $3478 \mathrm{~cm}^{-1}$ corresponds only to the $\mathrm{Ow}-\mathrm{Hw}$ stretching. This interpretation contrasts with the empirical band assignment based on H-D ...A distances (Table 6). However, it should be noted that the difference between the two experimental stretching frequencies (3566 and $3517 \mathrm{~cm}^{-1}$ ) is less than $50 \mathrm{~cm}^{-1}$. Moreover, deviations from regression lines (Libowitzky 1999) arise as a consequence of different $\mathrm{H}$ bonding geometry (e.g., bent vs straight; bifurcated bonds) or because of factors not related to the $\mathrm{H}$ bond itself such as cationic influences. In particular, the $\mathrm{O} 41-\mathrm{H} 41 \cdots \mathrm{Ow}$ hydrogen bond is stronger bent $\left(\mathrm{DHA}=138(6)^{\circ}\right)$ compared to the $\mathrm{Ow}-\mathrm{Hw} \cdots \mathrm{O} 23\left(\mathrm{DHA}=157(8)^{\circ}\right)$.

A final conclusion can be drawn on the double peak observed at 3570 and $3481 \mathrm{~cm}^{-1}$ in the VDOS curve of the $\mathrm{Ow}-\mathrm{Hw}$ interaction (Fig. 6b). In principle, such splitting is a potential indication of a bifurcated $\mathrm{H}$ bond. According to X-ray data collected at RT, in addition to the $\mathrm{Ow}-\mathrm{Hw} \cdots \mathrm{O} 23$ connection the $\mathrm{Ow}-\mathrm{Hw} \cdots \mathrm{O} 41$ interaction could also be considered in spite of the unfavorable DHA angle $\left(104(6)^{\circ}\right)$. The Hw…041 distance, 2.58(9) $\AA$, corresponds to a stretching frequency of $3622 \mathrm{~cm}^{-1}$ (Libowitzky 1999). Thus, a dynamic configuration with Hw hydrogen bonds towards $\mathrm{O} 23$ and $\mathrm{O} 41$ acceptors can be suggested. This interpretation could explain the apparent contradiction between the empirical band assignment and that based on theoretical calculations. Interestingly, the lawsonite structure also shows strongly bent and bifurcated $\mathrm{H}$ bonds (Libowitzky and Rossman 1996).

\section{Discussion}

Our results demonstrate that the structure of noelbensonite determined at RT corresponds to the low-temperature $\left(-118^{\circ} \mathrm{C}\right)$ structure of lawsonite (Libowitzky and Armbruster 1995) and to the phase of hennomartinite below $95^{\circ} \mathrm{C}$ (Libowitzky and Armbruster 1996). Thus, the three minerals are isostructural and the mechanism involved in the phase transition is of the same type. However, the transformation from space group $P 2_{1} c n$ to $\mathrm{Cmcm}$ in noelbensonite also involves a rotation of Si tetrahedra and not only a change of the hydrogen orientation. Such modification is indicated by the increase of the $\mathrm{Si}-\mathrm{O} 1-\mathrm{Si}$ angle from $155.6(4)^{\circ}$ at room temperature to $160.00(9)^{\circ}$ at $275^{\circ} \mathrm{C}$. Thus, the noelbensonite framework seems to be less rigid compared to that of lawsonite and hennomartinite in which the corresponding angle only showed a change of ca. $1^{\circ}$.

In general, atomic positions and orientation of hydrogen bonds are approximately the same as those determined for hennomartinite. Nevertheless, in our experiment, inspection of difference Fourier maps did not indicate the occurrence of split atomic positions for hydrogen as found in the hennomartinite $P 2_{1} c n$ structure. Moreover, the complicated twin-disorder pathway of hennomartinite during subsequent heating and cooling experiments (Libowitzky and Armbruster 1996) was not observed in noelbensonite that behaves reversibly (Fig. 2). The behavior of hennomartinite was explained by the irreversible growth of large twin domains during the first heating cycle. The crucial structural evolution occurred during the first heating cycle and the initial state could not be recovered. Subsequent annealing or quenching did not produce any additional domain evolution. In contrast, the noelbensonite phase transition is always reversible indicating either a different behavior with respect to that of the $\mathrm{Sr}$ analogue or our sample already experienced a first heating process.

The symmetry evolution in lawsonite also includes an intermediate phase transition $P 2_{1} c n-P m c n$, and the average space group Pmcn was also suggested for hennomartinite (Libowitzky and Armbruster 1996). Test refinements in Pmcn were also performed for the noelbensonite structure at 100,150 , and $200^{\circ} \mathrm{C}$ but this led to unsatisfactory $R$ values and high residuals in difference Fourier maps. It is interesting to point out that the $P 2_{1} c n-P m c n$ phase transition in lawsonite is not as apparent as the Pmcn-Cmcm transition. The Pmcn structure is stable between -118 and $0{ }^{\circ} \mathrm{C}$ (Libowitzky and Armbruster 1995). In hennomartinite, Pmcn symmetry was only proposed (no structural refinement) in the temperature range from 95 to $150^{\circ} \mathrm{C}$, an even narrower field compared to that of lawsonite. Therefore, it could well be that the same transformation occurs in noelbensonite but it is even less evident than that in hennomartinite, or the stability field is not large enough to be resolved by our experiments.

Lawsonite single crystals were investigated by polarized FTIR spectroscopy showing that the room temperature structure $(\mathrm{Cmcm})$ contains a dynamically disordered $\mathrm{H}_{2} \mathrm{O}$ molecule and also disordered $\mathrm{O}-\mathrm{H}$ orientations in hydroxyl groups, suggesting that the lawsonite phase transitions are of a dynamic order-disorder type rather than of displacive type (Libowitzky and Rossman 1996). Our experimental results and theoretical calculations showed that the $\mathrm{H}_{2} \mathrm{O}$ molecule in the $\mathrm{Cmcm}$ structure of noelbensonite is also affected by positional disorder. The disordered arrangement of $\mathrm{H}$ atoms results in a dynamic displacement of the $\mathrm{Ow}$ site above and below the (100) mirror plane. In contrast, 
the $P 2_{1} c n$ structure represents an ordered distribution, with Ow either above or below the mirror plane characteristic of space group $\mathrm{Cmcm}$.

The effects of the incorporation of a larger cation in the cavities of the lawsonite-type structure has already been discussed by several authors (Liebscher et al. 2010; Ende et al. 2016). As demonstrated for synthetic "Pb-lawsonite" (Ende et al. 2016), hennomartinite (Libowitzky and Armbruster 1996) and noelbensonite (this study), the main effect is the shift of the phase transitions toward higher temperatures. In our study the transition temperatures are practically the same as those determined for hennomartinite. Both noelbensonite and hennomartinite octahedra are occupied by $\mathrm{Mn}^{3+}$, the size of cavities is increased and the structure has more freedom to develop the more favorable ordered configuration $\left(P 2_{1} c n\right)$. Thus, in the two minerals this structure is stable in the same temperature range. On the other hand, synthetic "Pb-lawsonite" behaves, upon heating, differently from natural $\mathrm{Ca}$ end-member lawsonite, despite the same cation $(\mathrm{Al})$ in the octahedra. Although a similar phase transition (Pmcn $\rightarrow \mathrm{Cmcm}$ ) occurs for " $\mathrm{Pb}$ lawsonite" at $172{ }^{\circ} \mathrm{C}$, the structural change seems to be due to the interaction of the $\mathrm{SiO}_{4}$ tetrahedra and $\mathrm{AlO}_{6}$ octahedra with the $\mathrm{Pb}^{2+}$ cation, which is significantly larger than $\mathrm{Ca}^{2+}$ (Ende et al. 2016). Synthetic Sr-rich lawsonite is monoclinic $\left(P 2_{1} / m\right)$ at RT when quenched from ca. $4 \mathrm{GPa}$ and $600^{\circ} \mathrm{C}$ and the decreased symmetry has been ascribed to the tilting and rotation of the $\mathrm{Si}_{2} \mathrm{O}_{7}$ groups (Liebscher et al. 2010). In contrast, Cmcm symmetry has been proposed for natural "Sr-lawsonite," itoigawaite investigated by X-ray powder diffraction at RT (Miyajima et al. 1999). Thus, the role of the cavity occupants and octahedral cation has to be considered as a combined effect on the crystal structure of the lawsonite group members, influencing the stability range of various modifications and the associated net of hydrogen bonds.

Acknowledgements We are thankful to Alfons Berger for technical support during SEM-EDX analyses. Authors acknowledge access to the HPC resources at the University of Bern and the CRAY-XE at the Swiss Center of Scientific Computing at Lugano. The review and useful comments of Eugen Libowitzky and of an anonymous reviewer are highly appreciated.

\section{References}

Baur WH (1978) Crystal structure refinement of lawsonite. Am Mineral 63:311-315

Brehm M, Kirchner B (2011) TRAVIS - a free analyzer and visualizer for monte carlo and molecular dynamics trajectories. J Chem Inf Model 51:2007-2023
Brese NE, O'Keeffe M (1991) Bond-valence parameters for solids. Acta Cryst B 47:192-197

Churakov SV, Wunder B (2004) Ab-initio calculations of the proton location in topaz-OH, $\mathrm{Al}_{2} \mathrm{SiO}_{4}(\mathrm{OH})_{2}$. Phys Chem Miner 31(3):131-141

Cockayne E, Levin I, Wu H, Llobet A (2013) Magnetic structure of bixbyite alpha- $\mathrm{Mn}_{2} \mathrm{O}_{3}$ : a combined DFT+ $\mathrm{U}$ and neutron diffraction study. Phys Rev B87 (18): 1-11

Coombs DS, Kawachi Y, Miura H, Chappell D (2004) Cerchiarite and Ca-bearing noelbensonite from Woods mine, New South Wales, Australia. Eur J Mineral 16:185-189

Ende M, Wunder B, Koch-Müller M, Pippinger T, Buth G, Giester G, Lengauer CL, Libowitzky E (2016) T-induced displacive phase transition of end-member Pb-lawsonite. Mineral Mag 80:249-267

Ferraris G, Ivaldi G (1988) Bond valence vs bond length in $\mathrm{O} \cdots \mathrm{O}$ hydrogen bonds. Acta Cryst B 44:341-344

Grimme S (2007) Semiempirical GGA-type density functional constructed with a long-range dispersion correction. J Comput Chem 27:1787-1798

Hartwigsen C, Goedecker S, Hutter J (1998) Relativistic separable dual-space Gaussian pseudopotentials from $\mathrm{H}$ to $\mathrm{Rn}$. Phys Rev B 58(7):3641-3662

Kawachi Y, Coombs DS, Miura H (1996) Noélbensonite, a new BaMn silicate of the lawsonite structure type, from Woods mine, New South Wales, Australia. Mineral Mag 60:369-374

Libowitzky E (1999) Correlation of O-H stretching frequencies and $\mathrm{O}-\mathrm{H}$ hydrogen bond lengths in minerals. Monatshefte Chem 130: 1047-1059.

Libowitzky E, Armbruster T (1995) Low-temperature phase transitions and the role of hydrogen bonds in lawsonite. Am Mineral 80:1277-1285

Libowitzky E, Armbruster T (1996) Lawsonite-type phase transitions in hennomartinite, $\mathrm{SrMn}_{2}\left[\mathrm{Si}_{2} \mathrm{O}_{7}\right](\mathrm{OH})_{2} \cdot \mathrm{H}_{2} \mathrm{O}$. Am Mineral 81:9-18

Libowitzky E, Rossman GR (1996) FTIR spectroscopy of lawsonite between 82 and $325 \mathrm{~K}$. Am Mineral 81:1080-1091

Liebscher A, Dörsam G, Franz G, Wunder B, Gottschalk M (2010) Crystal chemistry of synthetic lawsonite solid-solution series $\mathrm{CaAl}_{2}\left[(\mathrm{OH})_{2} / \mathrm{Si}_{2} \mathrm{O}_{7}\right] \cdot \mathrm{H}_{2} \mathrm{O}-\mathrm{SrAl}_{2}\left[(\mathrm{OH})_{2} / \mathrm{Si}_{2} \mathrm{O}_{7}\right] \cdot \mathrm{H}_{2} \mathrm{O}$ and the Cmcm-P $2_{1} / m$ phase transition. Am Mineral 95:724-735

Lucchetti G, Cortesogno L, Palenzona A (1988) Low-temperature metamorphic mineral assemblages in $\mathrm{Mn}-\mathrm{Fe}$ ores from Cerchiara mine (northern Apennine, Italy). Neues Jahrbuch für Mineralogie Monatshefte (8):367-383

Miyajima H, Matsubara S, Miyawaki R, Ito K (1999) Itoigawaite, a new mineral, the $\mathrm{Sr}$ analogue of lawsonite, in jadeite from the Itoigawa-Ohmi district, central Japan. Mineral Mag 63(6):909-916

Perdew JP, Burke K, Ernzerhof M (1996) Generalized gradient approximation made simple. Phys Rev Lett 77(18):3865-3868

Perdew JP, Burke K, Ernzerhof M (1997) Errata: generalized gradient approximation made simple. Phys Rev Lett 78(7): 1396 (Phys Rev Lett 77, 3865 (1996))

Resta R (1994) Macroscopic polarization in crystalline dielectrics: the geometric phase approach. Rev Mod Phys 66:899

Salje EKH, Crossley S, Kar-Narayan S, Carpenter MA, Mathur ND (2011) Improper ferroelectricity in lawsonite $\mathrm{CaAl}_{2} \mathrm{Si}_{2} \mathrm{O}_{7}(\mathrm{OH})_{2} \cdot \mathrm{H}_{2} \mathrm{O}$ : hysteresis and hydrogen ordering. $\mathrm{J}$ Phys: Condens Matter 23:222202

Salje EKH, Gofryk K, Safarik DJ, Lashley JC (2012) Order-parameter coupling in the improper ferroelectric lawsonite. J Phys Condens Matter 24:255901 
Sheldrick GM (2008) Crystal structure refinement with SHELX. Acta Cryst A64:112-122

Sheldrick GM (2015) Crystal structure refinement with SHELX. Acta Cryst C71: 3-8

VandeVondele J, Hutter J (2007) Gaussian basis sets for accurate calculations on molecular systems in gas and condensed phases. $\mathbf{J}$ Chem Phys 127:114105
VandeVondele J, Krack M, Mohamed F, Parrinello M, Chassaing T, Hutter J (2005) QUICKSTEP: Fast and accurate density functional calculations using a mixed Gaussian and plane waves approach. Comput Phys Commun 167(2):103-128 